\title{
Who We Are Is What Makes Us Laugh: \\ Humour as Discourse on Identity and \\ Hegemony
}

\author{
CHRISTIAN YLAGAN
}

\begin{abstract}
There exists a sociocultural function to humour that is geared towards maintaining order through a subversion (or inversion) of the more serious, structured status quo, and while there is a pragmatic side to the dispensation of humour across any given society, humour can also serve a fundamentally ontological function in determining and representing a group's identity. Though notions of social organization and culture exist and are perpetuated primarily within a group's literary canon, as espoused for example in the privileging of genres such as the epic or the novel as loci of national identity, this paper argues that such identities can be just as effectively - if not better - constructed through popular representations in humour, especially in satirical content found in "ephemeral" mediums such as comic strips. Such representations in turn can be mobilized to complement or even dismantle the status quo and offer alternative paradigms of understanding national identities and cultural affiliations.
\end{abstract}

Keywords: postcolonial; humour; satire; national identity; Filipino literature; popular literature

While François Rabelais once said that "to laugh is proper to man", in truth, laughter is primarily an innate physiological function, underscored by how infants and even certain animals have the capacity to do so as a form of emotional release. On the contrary, humour requires a certain epistemological and metalinguistic disposition to think in abstraction, symbols, and irony. Thus, while both laughter and humour have undeniable social aspects, humour is more "properly human" in that it is the mode that carries the nuances of language, culture, and context.

There are numerous theories of humour, with the most notable being "incongruity theories" and "social theories". Incongruity theories of humour focus on the cognitive aspect of humour, specifically the subversion of expectations, whether linguistic/auditory (as in punning), or diegetic (as in irony), that lends a narrative or text humorous. Incongruity theories are hinged on 
the notion that laughter arises from the relationship between two or more objects, events, or concepts that are expected to function as elements of a single complex signification, but instead appear as disjointed or mismatched. Kant emphasizes this quality of surprise and unexpectedness in humour in his Critique of Judgment when he claims that "laughter is an affect resulting from the sudden transformation of a heightened expectation into nothing" (2000: 209). Meanwhile, social theories of humour focus on its necessarily inclusionary/exclusionary nature, highlighting how specific elements of humour such as language and cultural context serve to foster a semblance of social segregation among those who are "in" on the joke, those who are the butt of it, and those who do not get it. Social theories of humour emphasize how the humorous effect that leads to the inclusionary/exclusionary dynamic is hinged not merely on linguistic cleverness, but on the very social and cultural context that renders this very incongruity possible in the first place. Both theoretical categories point to a possible correlation between humour and Claude Levi-Strauss' concept of mythology, in that humour, like mythology, provides an ordered and intelligible way with which to experience a chaotic reality. Patrick O’Neill observes that "mythical thought [...] always progresses from the awareness of oppositions towards their resolution [and] this is also the most characteristic feature [...] of humour" (1990: 104). Through a kind of intellectual bricolage that compensates for the inadequacies of traditional discourse, humour functions as a coping mechanism for understanding uncertainty in reality and a tool for making sense of the contradictory or intractable.

Jeroen Vandaele observes that "the particular problem with [transmitting] humour is that humour relies on implicit knowledge... [including] implicit cultural schemes (to be breached for incongruous purposes; to be known for the purposes of rendering something funny) and has its rules and taboos for targeting" (2010: 150). In the Philippines for example, "mother" and "martial law" jokes are considered bad taste; in contrast, joking about people with disabilities is acceptable. Furthermore, that humour is also reliant on metalinguistic communication - seen in the dynamics of denotation/ connotation, timing, and perhaps even gestures - is important in transmitting humorous intent. Because the rules, expectations, and agreements on social play are often group- or culture-specific, humour is therefore without doubt a distinctly human thing because our symbolic mind, socialized within a specific human context, can turn uncertainty, surprise and danger into what we call humour. 
There exists a sociocultural function to humour that is geared towards maintaining order through a subversion (or inversion) of the more serious, structured status quo, and while there is a pragmatic side to the dispensation of humour across any given society, humour can also serve a fundamentally ontological function in determining and representing group's identity. Though traditional notions of social or even national identity exist within a group's literary canon, this paper argues that such identities can be as effectively constructed through representations in humour, and that such sociocultural representations could be mobilized to complement or even dismantle the status quo.

\section{Traditional Canons: Representing Group Identity in National Novels}

The national novel has traditionally been the genre used to depict group identity in literature, and over the years, the genre has expanded to accommodate functions other than pure mimesis. Nowhere do we see such extraneous functions more clearly at work than in the dynamics of national canons in the realm of world literature, where texts contain contextual import of a sociocultural and political nature in their reception and assimilation into existing knowledge. The genre of the novel has, in essence, acquired a metonymic function as representation of cultural identity.

But identity itself is not a static concept; it is both a by-product and field of contestation among opinions, values, and cultures whose multivocalities are not always necessarily harmonic. Identity, therefore, can best be characterized as a democratic (and democratizing) construction among stakeholders. This pluralistic, rhizomatic view of identity runs counter to the prevailing notion that the nation - and correspondingly, its representative literature - is monolithic and homogeneous, with the political and intellectual elite as its vanguard. Outside the Philippines' basic education curriculum, for example, José Rizal's national novels Noli Me Tangere and El Filibusterismo are hardly referenced as community-defining despite their avowed historical and literary significance. What this shows is that texts are entrenched in economies of value, or a hierarchization that privileges one discourse over another, either because of ethnolinguistic disparities or sociopolitical inequalities. Because canonical texts are primarily written to represent an institutional view of national identity, there must exist a divergent notion of nation that is located extrinsic to this tradition. The national narrative therefore can be said to exist as a pliable concept within the contestatory poles of canon, and national 
novels no longer hold the sole distinction of being the locus of cultural identity. Instead, popular texts, especially humorous ones, can be seen as possible fields of creating and transmitting a complementary group-view or identity.

\section{The Discourse of Humour and Satire as its Vehicle}

In his Prison Notebooks, Antonio Gramsci talks about the concept of the "national-popular", where he discusses why in Italy there was the problem of "the non-circulation of artistic literature among the people; and that of the nonexistence of a popular literature" (Gramsci 1985: 206). Gramsci attributes these problems to the fact that

'writers' and 'people' do not have the same conception of the world. In other words the feelings of the people are not lived by the writers as their own, nor do the writers have a 'national educative' function: they have not and do not set themselves the problem of elaborating popular feelings... [Thus] the lay forces (intellectuals) have failed in their historical task as educators and elaborators of the intellect and moral awareness of the people-nation. They have been incapable of satisfying the intellectual needs of the people precisely because they have failed to represent a lay culture... as was necessary from the national point of view, and because they have been tied to an antiquated world, narrow, abstract, too individualistic or caste-like. (Gramsci 1985: 207, 211)

There exists in Gramsci a recognition of a (supposedly) superior group whose tastes are imposed on the (seemingly) unknowing masses, but who are also criticized for presenting a narrow view of the milieu. Popular culture then for Gramsci is both a meaningful ideological sphere that molds the consciousness of subaltern groups through the workings of the intellectual elite, and is also thus the venue for contestation for the organic intellectual. Gramsci's critique of the intellectual elite, whose aesthetic tastes and valuations are constantly indoctrinated upon those outside it, is suggestive of a balance among the state (whose machinery allows the perpetuation of this indoctrination), the civil society (the public space where contestation happens), and the private sphere (whose response is key to the outcome of indoctrination) (Mascha 2011: 195). Gramsci's argument seems to reinforce Raymond Williams' assertion that "culture is ordinary", a notion that describes a particular way of life "which expresses certain meanings and values not only in art and learning but also in institutions and ordinary behavior" (1961: 57). These collective habits, assumptions, routines, languages, and preferences create a shared value system that define the culture of a group, which in turn allow people to 
organize around the concept of Benedict Anderson's imagined community. Globalization and mass production have multiplied and fragmented forms of cultural capital, which has resulted to popular culture becoming "a prime site for contestations of value" (Edensor 2002: 16). Civil society then becomes the motor of history, for this is "where the meanings and values that can sustain or transform society are created" (Jones 2000: 33), and because it is the "location of all culture or 'ethical' life publicly expressed" (Mascha 2011: 195). Nowhere do we see this transformative awareness and dynamic groupthink more acutely than in humour, and more specifically, in the sub-realm of satire.

\section{Defining Boundaries of Group-Think through Satire}

Satire is an example of counter-hegemony because of its function in subverting the pervasive discourse in the status quo. As a counter-hegemonic discourse, satire operates as a "war of position, since it smoothly degrades official discourse by revealing [its] weak aspects and not by actually confronting the [dominant discourse]" (Mascha 2011: 196). Texts that employ satire derive their humour from a meta-utilization of a particular culture, a system of institutions, and frameworks of belief and knowledge that allow such texts to function within a dynamic of higher-order discourse. Paul Simpson refers to an organic set of frames of references that satirical texts employ in relation to a humorous impetus, which "emanates from a perceived disapprobation, by the satirist, of some aspect of a potential satirical target" (2003: 8). The satirical model of humour is thus configured around a tripartite of discursive subject positions that perpetually shift and are constantly negotiated: compared to other communicative models that merely focus on the discourse between speaker and receiver, satire acknowledges the fundamental importance of the satirized, the target attacked or critiqued in the discourse, without whom there would be no joke. Thus, the relationship between the satirist (producer) and the satiree (receiver) is one of communicative ratification or validation hinged on an "ex-collusion" (Simpson 2003: 8) of the satirized, that is, a critiqueobjectification of the satirized into the discourse. The satirized is hence drawn into the discourse but is excluded from it; the satirized provides the impetus for interaction to happen between the satirist and satiree. Insofar as the satirized draws from a set of common references, values, and cultural knowledge in order to sublimate the satirized into a position of inferiority for the satiree, there exists a fair amount of calculated interactive risk in the production and transmission of satirical discourse. This satirical relationship is facilitated by a discoursal prime, which "activates a putative or real anterior discourse 
event, mediated intersemiotically... and in this sense is an 'echoic' utterance to the extent that it is predicated on someone else's discourse, but over which ironic distance is placed through a repositioning of the ostensible speaking source of the text" (Simpson 2003: 8-9). The prime, as a framework of general knowledge, is engaged in an oppositional relationship with the dialectic elements of textual structure, such that irony and humour is produced. This relationship creates what Karl Popper calls a "force", which leads to a resolution that embodies a new idea. In his own words,

the only 'force' which propels the dialectic development is, therefore, our determination not to accept, or to put up with, the contradiction between thesis and antithesis. It is not a mysterious force inside these two ideas, not a mysterious tension between them, which promotes development - it is purely our decision, our resolution not to admit contradictions, which induces us to look for a new point of view (Popper 1963: 317).

Popper seems to be talking about the emergence of congruity amid the incongruity, what we can call the humorous "uptake". For there to be a valid uptake, the satiree must be able to see that there is a heuristic aspect to the satirical text, that is, that there is an extralinguistic meaning to the text that needs to be discovered outside its denotative elements. The satirical method can thus be seen as a complex discursive structure into which various other techniques (visual, verbal, etc.) may be incorporated.

The function of satirical humour, especially in the Philippine setting, extends beyond entertainment or merely making fun of the satirized. Essentially, satire constitutes sites where individuals can (and do) negotiate identities and group affiliations; in effect, satire becomes an important solidarity strategy that contributes to the construction and reinforcement of complex social identities, helping establish and maintain social boundaries and affiliations. Corollary to this, satirical humour allows individuals recourse to challenge normative and expected behaviours towards the satirized, who are often individuals that come from groups of hegemonic importance. According to Gramsci, subaltern groups are "potentially capable of being united - of being organized into the "people versus the power bloc' - if their separate struggles are connected" (Mascha 2011: 200-201), and it is this potential unity that allows for such groups to move towards self-determinism. Instead of drawing group boundaries based solely on class, humour then allows individuals to organize themselves based along socalled "communities of practice" (Holmes \& Stubbe 2003; Holmes \& Schnurr 2005), where norms are "typically negotiated and enacted on a day-to-day basis... [and wherein] people dynamically construct and negotiate their membership" 
(Schnurr \& Holmes 2005: 103). These communities of practice are "[aggregates] of people who come together around mutual engagement in a behavior. Ways of doing things, ways of talking, beliefs, values, power relations - in short, practices - emerge in the course of this mutual behavior" (Eckert \& McConnellGinet 1992: 464). While satirical humour constitutes a narrow aspect of a community of practice's shared experience, it is an important one because it allows people to organize along lines of mutual engagement towards a joint, negotiated enterprise such as social critique, and using a shared repertoire of culture, values, experiences, etc. developed over a period of time (Wenger 1998; Schnurr \& Holmes 2005: 103). Humour thus becomes "one of a wide variety of linguistic and pragmatic strategies available [especially] to those 'out of power' to construct a positive identity, and also to subvert the pervasive influence of the dominant group by testing, stretching, and contesting normative boundaries" (Vine et al. 2009). In this sense, satire can become an important barometer for representing social identities, as well as agendas of communities of practice, that predominate and interact at any given time.

\section{Organizing Lines of Belonging in Three Comic Strips}

Pol Medina's Pugad Baboy (Swine's Nest ${ }^{1}$ ) is perhaps the most widely recognized comic strip in the Philippines. Having been in circulation since 1988, the comic strip appeared exclusively in the sheets of the Philippine Daily Inquirer, then went digital at online news site Rappler.com in June 2013, before finally moving back to serialized print publication in the Philippine Star in March 2018. The comic strip features a fictional Filipino community composed of mostly obese or overweight people and their day-to-day adventures in dealing with the idiosyncrasies of Philippine life. Pugad Baboy has carved a niche for itself as an important venue for representing the pulse of Filipino domestic life, as well as general Filipino sentiments on important social issues. Poverty, government corruption, bourgeois sensibilities, celebrity gossip, and even popular culture are the usual fodder for Pugad Baboy issues. At its core, Pugad Baboy demonstrates a strong penchant for social satire and sharp, tongue-incheek witticism directed at figures or events in current events. Primarily, Pugad Baboy is known for its commentary on sociopolitical issues, such as corruption in the government, as the following strips from volume 55 of Medina's comics show.

This and other translations or interpretations of text in Medina's comic strips that appear in this article are my own. 
STRIP\#1: An overweight senator tells Polgas, an anthropomorphic dog character in Pugad Baboy, that he lost weight during Holy Week because he ate fish for three consecutive days, which Polgas attributes to the weight-reducing properties of lean fish (Panel 1). The politician disagrees, saying that during the Holy Week, he mainly ate raw fish at a Japanese restaurant, which led him to contract explosive diarrhea (Panel 2). He then describes the experience of going to the bathroom, much to Polgas' chagrin and disgust (Panels 3 and 4).

STRIP\#2: Mang Dagul, the owner of Polgas and main character of Pugad Baboy, asks the same senator if he believes in karma, citing how the senator's wife has been going through the experiences of being victimized in scams, losing money in casinos, etc. (Panel 1). The senator defends himself by saying that the real reason why he takes money from public funds is that his constituents keep asking for financial dole-outs (Panels 2 and 3). The senator blames his constituents for his corruption, and Mang Dagul breaks the fourth wall by telling the reader conspiratorially that it's our [the people's] fault (Panel 4).

STRIP\#3: Mang Dagul shares his disappointment with Polgas that the Philippines has been importing rice rather than growing its own, expressing fear that the Philippines will run out of food soon because exporting will get too expensive (Panels 1 and 2). Another politician then exclaims that he can live off of eating more cheaply and sustainably (Panel 3). He then delivers the punch line in the last panel, saying he's willing to eat "Pyoorpuds" (Purefoods, a local brand) ham, instead of the more expensive and imported jamon Ibérico.

In each of these examples, Pugad Baboy author Pol Medina is poking fun at the generally accepted view among Filipinos that politicians, especially lawmakers such as senators and congress representatives, are corrupt and out to pocket taxpayers' money. This view is predicated on a highly debated feature of the Philippine legislative system, the allocation of the Priority Development Assistance Fund (colloquially known as the "pork barrel") to each senator or representative. Disbursing the PDAF (usually benefitting their respective districts or pet projects) is essentially a matter of individual legislative discretion, and as such has been deeply controversial because of its obvious overlap with the executive arm of the government. The PDAF has also been widely challenged for its extreme potential for abuse, as was the case in the Pork Barrel Scam of 2013, wherein certain senators were alleged to have funneled Php 10 billion (Philippine pesos, or \$238 million CAD) to various dummy contractors and projects. Thus, we see that in the aforementioned examples, Pugad Baboy is presenting contestatory and almost belligerent views of politicians and their hypocritical stance towards the suffering of 
the greater majority of Filipinos. The first strip plays on the time-honoured custom of skipping red meat during Holy Week, one that is very much observed in Catholic Philippines. By depicting that the senator also engages in such a religious custom draws him into community of practice with the rest of the figures (and presumably us, as readers). Yet this depiction is subverted by the revelation that the senator's consumption of fish, which he uses as a base for organizing social affiliation, is disproportionate with the practice of the rest of the community, who live humbly and ascetically during Lent. By introducing the concept of "explosive diarrhea" that the senator contracted while consuming raw fish at a presumably high-end Japanese restaurant, the strip is inviting the reader to revel in a semblance of social aggression towards the satirized, redrawing the lines of community to ex-collude the politician. The first strip is especially poignant because it pokes fun not just at the indiscriminate corruption of a politician who lives beyond his means using taxpayers' money, but also exposes the hypocrisy of such politicians who use religion to curry favour with the electorate.

This attitude of patronage is then carried over into the second strip, and then makes fun of it through an act of meta-awareness. In the second strip, Mang Dagul asks the politician if he believes in $\mathrm{karma}^{2}$, seeing as how his wife has recently been incurring a lot of bad luck. Ironically, the instances of bad luck that the strip is referring to are, to a great extent, manifestations of poetic justice: the pyramiding scam implies they had been engaged in unsustainable and corrupt business practices; being victimized by a snatcher implies flaunting one's extravagant lifestyle in public so as to attract petty theft; and losing money in casinos implies vice and general misuse of resources. The senator then tries to justify his corruption by attributing it to his constituents' need for dole-outs, as implied in Panel 3 by the triple juxtaposition of petty expenses that he claims he uses taxpayers' money on (funeral expenses, passenger fares) with valid public needs (medicine, hospitalization) and his family's personal expenditures (in Panel 2, he talks about how every one of his family members needs a house, cars, and jewelry). In the last panel, the visual representation of Mang Dagul can be interpreted two ways: he is looking conspiratorially

2 The concept of karma in the Philippines is different from the Buddhist or Hindu one. The main difference lies in how it is generally thought of as incurring good or bad luck immediately or within one's life depending on one's acts, as opposed to the traditional belief that one's karma is reflected in the manner of one's reincarnation. Thus, the various instances of the senator's wife illustrated in the strip (e.g., being victimized in a pyramiding scam, getting mugged, losing money in a casino) are immediate "payback" effects of their corruption. 
at Polgas, or looking straight at the reader of the strip. Either way, he is sarcastically self-deprecating when he says, "Oh, it's our fault after all”. This strip focuses our attention on the inherent practices of patronage politics in the Philippines, a very real phenomenon that is aggravated by the presence of the PDAF. In invoking this issue in the strip, the author is commenting on a flaw of the community of practice, manifested in the social acceptance of patriarchal benefaction. The meta-awareness of Mang Dagul, however, delineates between those who are presumably aware of the issue and those who perpetuate it, and highlights the socially discursive aspect of this political phenomenon.

In the third strip, Mang Dagul laments the import policies of the country as he expresses wariness about the state of agriculture in the Philippines, punctuated by the fact that no one wants to be a farmer anymore (Panel 1). This points to two key cultural stereotypes held by many Filipinos: first, that foreign cultures and goods are superior to local ones, hence the presence of a strong mentality of materialism for all things foreign; second, that blue collar jobs such as farming are backward and unmodern, and are therefore undesirable career paths. The author thus satirizes communities of practice defined by such pseudo-bourgeoisie preferentiality in the third comic strip by using the politician as representative of such communities. In the strip, the senator claims a quasi-affiliation with the "masses" by mentioning how he can also survive on local and presumably cheaper products: he mentions the word "dildil", which literally means "make do", and is usually used in the phrase "mag-dildil ng asin", to make do with eating salt over rice (the phrase points to eating in extreme poverty, or having nothing to eat rice with except salt). However, the politician subverts this expectation of "eating salt with rice" by invoking the colonialist mentality previously mentioned: substituting salt with something equally salty but undoubtedly more expensive and bourgeois: ham. The strip satirizes the politician in three ways: first, for making concessions to maintain this quasi-affiliation, i.e., eating local ham instead of imported ham; second, for bastardizing the pronunciation of the local brand ("Purefoods" to "Pyoorpuds"), indicating that expensive taste does not necessarily equate to class (the accented mispronunciation as indicative of being pedestrian or trying too hard to be bourgeois); and third, for trying to align himself with the masses in an act of quasi-affiliation yet proving unable to adhere himself to the shared values and identity of the said community of practice (poverty, simplicity, etc.).

In each of these examples, we can see that the author employs satirical humour in order to draw the boundaries of certain communities of practice, in a deliberate attempt at demonstrating the inclusion-exclusion dynamic. These communities of practice largely intersect, as in the lines demarcating 
middle class-lower class, politician-electorate, or socially aware-apathetic. It is interesting to note that while the politicians are the most overtly satirized group in these strips, they are not the only one. The middle class, the electorate, and other groups are all fair game. Depending on the level of initiation into the shared sociocultural values or experiences, or the level of sophistication the reader has regarding humor norms, the comics negotiate across various communities of practice, and convey aggression on various levels and with varying degrees of intensity, with politicians bearing the brunt. The humorous elements allow the satirees to "manage their 'sociality rights' - the social expectancies and concerns over fairness, consideration, and inclusion in the group" (Schnurr and Holmes 2009: 115). Humour also allows for the attenuation of criticism towards the satirized. These multiple levels of interdiscursivity help us understand various ways in which humour contributes "in particular to the construction of power and distance relationships and particular social identities in [society, while also assisting] people in challenging and contesting... interactional norms" (Schnurr and Holmes 2009) prevalent around them. Through the discoursal construction of the satirical target through the collusion of shared social, cultural, and linguistic norms, satire is "far removed from the rarefied, ossified texts that characterize many of its "classical" components..., [and it is] conceptualized... as a form of dynamic social action which has palpable social and interactive consequences" (Simpson 2003: 187). One of these, of course, is the negotiation of a group mentality through contestations and applications of shared normative values.

\section{Defining Group Identity Through Humour}

Despite the organic representation of shared values and lines of community identity in popular texts, these have remained by and large stigmatized as lacking the necessary capital to be properly representative of certain cultural milieu or heritage. Theories of nationalism abound, yet most of these theories do not explore the more mundane aspects of the nation: things that exist in the day-to-day spaces of the popular. Dominant theories are primarily built upon an examination of cultural elements that exist as part of the "high" tradition, or what Edensor terms as "reified notions of culture" (2002: vi), which exist as a narrow aspect of the nation-space, and can be seen as a counterpoint to the changing nature of the popular. This changing nature is codified in one of the somewhat pejorative terms used to describe popular literature - "ephemera" a term that discounts the dynamic, multiple, and fluid nature of national representation. Accordingly, these multitudinous artifacts reflect the formation 
and representation of culture as much as the literature of the intellectual elite, if we accept Bennett's assertion that cultural identity is made up of "practices, institutions, and systems of classification through which there are inculcated in a population particular values, beliefs, competencies, routines of life and habitual forms of conduct" (1998: 28). In short, in dealing with the construction of a group identity, there must be an acknowledgment of the agency of consumers of culture insofar as their choices, purchases, reception, interpretations, appropriations, and uses of such cultural elements function as essential factors in making meaning and constructing identity (Storey 2010: 72). Janice Radway argues that there can be an increase in "articulating the differences between the repressive imposition of [bourgeois, elitist] ideology and oppositional practices that, though limited in their scope and effect, at least dispute or contest the control of ideological forms" (1987: 221-222), reinforcing the idea that culture is contingent upon contestation and synthesis.

The dialectic relationships between "elite" and "grassroots", "structure" and (consumer) "agency", "resistance" and "incorporation" highlight the concept of hegemony that Gramsci introduces in his works. As Storey notes, "a consumer, situated in a specific social context, always confronts a 'text' in its material existence as a result of particular conditions of production... [but] in the same way, a 'text' is confronted by a consumer, situated in a specific social context, who appropriates as culture, and 'produces in use' the range of possible meanings the 'text' can be made to bear [which] cannot just be read off from the materiality of the text, or from the means or relations of its production" (2010:5). Culture therefore cannot be pinned down to mere textuality or mere ideology; reception and the ensuing appropriation of such meaning into everyday life become the backbone for nation: something that we can find in the dialectic force of satirical humour. In short, meanings gleaned from and represented in texts do not just exist in their materiality, but are made meaningful in the dynamics of discourse. Foucault emphasizes that these discourses can be institutionalized by those in power to make their way of knowing circulate discursively in the world, effectively creating "regimes of truth" (Storey 2010: 6), of which national canons are one example. Like all constructs, however, this regime can be challenged through a critical evaluation not just of the texts in themselves, but also of the power relations that inform the negotiation and ritualization of the realities represented in such texts. It is therefore not enough to assume that "ordinary people - the masses consume because they have been infected with artificial wants dreamed up by the international league of producers, [nor would it be adequate to] treat [consumption] as a residual category - what people do when they are blocked 
from nobler activities like philanthropy, meaningful politics, and becoming mature" (Storey 2010: 139). Instead, credence must be given to popular literature as resistance texts whose "production in use", ideological effect, and incorporation can all provide an alternative and complementary view for the construction of the nation.

While we can concede that canonical texts remain dominant, it is interesting to note that outside the academia, these are texts that do not find themselves within the transactional paradigm of general consumption, highlighting the reality that "people's engagement with the world of commodities [of which popular texts are part] utilizes shifting frames of reference" (Edensor 2002: 113), as shown in how consumers may be drawn to "unintelligent" popular commodities while acknowledging certain exemplary national products. These shifting frames of reference allow us to see national taste, culture, and identity as unfixed elements within the domestic space, and emphasize how the sociocultural imaginary is an exercise of agency in dialogue with existing ideological structures of selfhood.

\section{Conclusion}

Johannes Fabian contends that cultural critics should be wary of reducing the popular to a mere numbers game, especially since "it is easy to qualify, perhaps dismiss, such a critique of culture as populist, that is motivated by political, even demagogic interests...[but] political, partisan commitment is not what ultimately gives strength to arguments based on the study of popular culture... [instead] the strength of popular culture derives from the fact that it is an ongoing process, that power is constantly established, negated, reestablished" (Fabian 1998: 131; 133). It must not deny unity or purity where they are real; instead, "they must be rejected where they become criteria defining what counts as real" (Fabian 1998: 132). Our understanding of social satire, humour, and popular culture in general as the possible habitus of group identity must account for dialectics because group identity itself is constantly fluid, changing, and historical (i.e., existing within a temporal-spatial context). In many humour situations, the intellect, like the artist, fluctuates back and forth among multiple possibilities, and the laughable becomes a link with the transcendental, "measuring the finite no longer against the equally finite but against the infinite and finding the contrast infinitely ludicrous" (O’Neill 1990: 43). As Vine et al. note, "boundary-marking humor...constructs and reinforces cultural identity... [and through it,] individuals shape and reshape identity... [Humor thus becomes] a flexible discourse strategy, which can be manipulated in a wide 
variety of ways" (2009: 126; 128). In trying to locate communitarian values in popular texts, we must engage three important factors: changing cultural sensibilities reflected in content, multiplicity in forms, and development of linguistic conventions.

These factors introduce certain difficulties in trying to reconcile popular culture with national identity. First, because popular literature (and satirical humour especially) represents dynamic sociocultural sensibilities and changes in linguistic conventions, we must also recognize that the notion of identity that informs such literature must also remain pliable and fluid. If identity is negotiated, it is negotiated within the boundaries of social and historical phenomena that constantly invite us to apply or modify our values and norms. Second, the reality of having multiple group identities representing diverse but coexisting cultures is apparent; each individual, as we have seen, negotiates his or her social realities across various communities of practice, which in themselves overlap and turn in on each other. Lastly, this calls into question the notion of canon itself, and whether such a categorization is really nothing more than a necessary fiction, especially in the context of fragmentary contexts. Humour, and satire specifically, annihilates not the individual, but the infinite, through the contrast with the status quo and the ideal. In the presence of this infinite fragmentation and incongruity, meaning and identity are yet to be determined, and so our laughter is both melancholy and great: something that Baudelaire touches upon when he claims that "laughter is likewise a token of the essentially contradictory nature of the human condition, torn between infinite grandeur and infinite misery" (O’Neill 1990: 44). Ultimately, these are tensions that need to be contended with in making sense of the dynamics of canon with counter-canon (or perhaps sub-canon?) in order to arrive at a dynamic stratum of identity. Looking at satire, and humour in general, merely opens an alternative horizon for us to arbitrate who we are, what we're about, and where we as a group can go.

\section{Christian Ylagan}

cylagan2@uwo.ca

Comparative Literature Program - Department of Modern Languages and Literatures

Western University

University College 2210

London, ON,

CANADA N6A 3K7 
Who We Are Is What Makes Us Laugh

\section{Bibliography}

Bennett, T. 1998. Culture: A Reformer's Science. London: Sage. Print.

Eckert, P.; McConnell-Ginet, S. 1992. Think Practically and Look Locally: Language and Gender as Community-based Practice. - Annual Review of Anthropology, 21, 461-490.

Edensor, T. 2002. National Identity, Popular Culture, and Everyday Life. Oxford \& New York: Berg.

Fabian, J. 1998. Moments of Freedom. Charlottesville; London: UP of Virginia.

Gramsci, A. 1985. Selections from Cultural Writings. Ed. by D. Forgacs and G. NowellSmith. Trans. By W. Boelhower. London: Lawrence and Wishart.

Holmes, J.; Schnurr, S. 2005. Politeness, Humour, and Gender in the Workplace: Negotiating Norms and Identifying Contestation. - Journal of Politeness Research: Language, Behaviour, Culture, 1, 121-149.

Holmes, J.; Stubbe, M. 2003. Power and Politeness in the Workplace: A Sociolinguistic Analysis of Talk at Work. London: Longman.

Jones, S. 2006. Antonio Gramsci. London; New York: Routledge.

Kant, I. 2000. Critique of the Power of Judgment. Ed. by P. Guyer. Trans. by P. Guyer and E. Matthews. Cambridge: Cambridge UP.

Mascha, E. 2011. Mocking Fascism: Popular Culture and Political Satire as Counterhegemony. - V. Tsakona, D. E. Popa, eds., Studies in Political Humour. Amsterdam; Philadelphia: John Benjamins Publishing Company, 191-213.

Medina, P. Jr. 2013. Pugad Baboy 55. Manila: Pol Medina Jr. Novelties, 17.

O'Neill, P. 1990. The Comedy of Entropy: Humour/Narrative/Reading. Toronto: University of Toronto Press.

Popper, K. 1963. Conjectures and Refutations: The Growth of Scientific Knowledge. London: Routledge.

Radway, J. 1987. Reading the Romance. London: Verso.

Schnurr, S.; Holmes, J. 2009. Using Humor to Do Masculinity at Work. - N. Norrick, D. Chiaro, eds., Humor in Interaction. Amsterdam; Philadelphia: John Benjamins Publishing Company, 101-123.

Simpson, P. 2003. On the Discourse of Satire: Towards a Stylistic Model of Satirical Humour. Amsterdam; Philadelphia: John Benjamins Publishing Company.

Storey, J. 2010. Cultural Studies and the Study of Popular Culture. $3^{\text {rd }}$ ed. Edinburgh: Edinburgh UP.

Vandaele, J. 2010. Humor in Translation. - Y. Gambier. L. van Doorslaer, eds., Handbook of Translation Studies, Vol. 1. Amsterdam; Philadelphia: John Benjamins Publishing Company, 147-152.

Vine, B. et al. 2009. Boundary-marking Humor: Institutional, Gender, and Ethnic Demarcation in the Workplace. - N. Norrick, D. Chiaro, eds., Humor in Interaction. Amsterdam; Philadelphia: John Benjamins Publishing Company, 125-139.

Wenger, E. 1998. Communities of Practice: Learning, Meaning, and Identity. Cambridge: Cambridge UP.

Williams, R. 1961. The Long Revolution. London: Chatto and Windus. 